\title{
Identification of Periopathogens in Atheromatous Plaques Obtained from Carotid and Coronary Arteries
}

\author{
Verica Pavlic $\mathbb{D},,^{1,2}$ Dejan Peric $\left(\mathbb{D},,^{3}\right.$ Ivana Stosovic Kalezic $\mathbb{D}^{3},{ }^{3}$ Marwa Madi $\mathbb{D},{ }^{4}$ \\ Subraya G. Bhat $\left(\mathbb{0},{ }^{4}\right.$ Zlata Brkic $\left(\mathbb{0},{ }^{5}\right.$ and Danijela Staletovic $\oplus^{3}$ \\ ${ }^{1}$ Department of Periodontology and Oral Medicine, Medical Faculty University of Banja Luka, \\ 78000 Banja Luka, Bosnia and Herzegovina \\ ${ }^{2}$ Department of Periodontology and Oral Medicine, Institute for Dentistry Banja Luka, 78000 Banja Luka, Bosnia and Herzegovina \\ ${ }^{3}$ Clinic for Dentistry, Faculty of Medicine, University of Priština Kosovska Mitrovica, Kosovska Mitrovica, Serbia \\ ${ }^{4}$ Department of Preventive Dental Sciences, College of Dentistry, Imam Abdulrahman Bin Faisal University, Dammam, Saudi Arabia \\ ${ }^{5}$ Clinic of Dental Medicine, Faculty of Medicine of the Military Medical Academy, University of Defense, Belgrade, Serbia
}

Correspondence should be addressed to Danijela Staletovic; danijela.staletovic@med.pr.ac.rs

Received 21 March 2021; Revised 23 May 2021; Accepted 8 June 2021; Published 17 June 2021

Academic Editor: Iole Vozza

Copyright (C) 2021 Verica Pavlic et al. This is an open access article distributed under the Creative Commons Attribution License, which permits unrestricted use, distribution, and reproduction in any medium, provided the original work is properly cited.

\begin{abstract}
Increasing attention has been paid to the possible link between periodontal disease and atherosclerosis over the past decade. The aim of this study is to investigate the presence of five periopathogens: Porphyromonas gingivalis (P.g.), Aggregatibacter actinomycetemcomitans (A.a.), Tannerella forsythia (T.f.), Treponema denticola (T.d.), and Prevotella intermedia (P.i.) in atheromatous plaques obtained from the carotid and coronary arteries in patients who underwent coronary artery bypass graft surgery and carotid endarterectomy. Group I (carotid arteries) consisted of 30 patients (mean age: $54.5 \pm 14.8$ ), and group II (coronary arteries) consisted of 28 patients (mean age: $63 \pm 12.1$ ). Clinical periodontal examinations consisted of plaque index, gingival index, sulcus bleeding index, and periodontal probing depth and were performed on the day of vascular surgery. The presence of periopathogens in periodontal pockets and atherosclerotic vessels was detected using polymerase chain reaction. In both subgingival plaque and atherosclerotic plaque of carotid arteries, P.g., A.a., T.f., T.d., and P.i. were detected in $26.7 \%, 6.7 \%$, $66.7 \%, 10.0 \%$, and $20.0 \%$, respectively, while for coronary arteries, P.g. was detected in $39.3 \%$, A.a. in $25 \%$, T.f. in $46.4 \%$, T.d. in $7.1 \%$, and P.i. in $35.7 \%$. The presence of five periopathogens in carotid and coronary atherosclerotic vessels showed correlation in regard to the degree of periodontal inflammation. The present study suggests the relationship between periodontal pathogenic bacteria and atherogenesis. Further studies are necessary in relation to the prevention or treatment of periodontal disease that would result in reduced mortality and morbidity associated with atherosclerosis.
\end{abstract}

\section{Background}

Periodontal disease/PD is a chronic inflammatory disease that occurs in the teeth surrounding tissues in response to the presence of bacterial biofilm accumulation and characterized by complex host biofilm interactions $[1,2]$. It affects up to $90 \%$ of the worldwide population (approximately $75 \%$ of the general population is affected by mild forms of periodontal disease including gingivitis, while the remaining $15 \%$ of the population has a moderate or severe form of periodontal disease). Therefore, it is ranked as a sixth most prevalent disease affecting humans $[1,2]$. The presence of specific, pre- dominantly Gram-negative anaerobic pathogenic periodontal microorganisms/periopathogens, such as Porphyromonas gingivalis (P.g.), Aggregatibacter actinomycetemcomitans (A.a.), Tannerella forsythia (T.f.), Treponema denticola (T.d.), and Prevotella intermedia (P.i.), and abnormal host response to periodontal disease are the key determinants of the onset and progression of periodontal disease [3]. In recent years, special attention has been paid to the possibility that the presence of periopathogens may influence systemic health [4-6].

Atherosclerosis is a chronic progressive narrowing of arteries that may lead to occlusion as a consequence of lipid 
deposition [2]. It underlies coronary heart disease (80\%), as well as myocardial and cerebral infarctions, therefore having a big socioeconomic importance [4]. The significant evidence proving the role of chronic inflammation in the pathogenesis of atherosclerosis and the destabilization of existing atheromatous plaques in the arteries has led many researchers to focus their attention to a search for the cause of the inflammation [7]. The link between periodontal disease and atherosclerosis was firstly given in 1963, when $25 \%$ higher risk of atherosclerotic plaque formation in a group of patients with periodontal disease was demonstrated $[8,9]$. Since then, there is a growing amount of evidence regarding the contribution of chronic inflammation and presence of periopathogens seen in periodontal disease and the enhanced risk of atherosclerosis [7-10]. Increasing evidence over the past decade suggests that periopathogens from periodontal pockets can enter the systemic circulation directly and may be present in peripheral organs, such as atheromatous plaques of different blood vessels. The second mechanism proposed includes increasing levels of inflammatory mediators, such as lipopolysaccharides and other products from periopathogens' cell breakdown that may stimulate inflammatory cytokines, upregulate endothelial adhesion molecules, and induce a prothrombotic environment, enhancing the risk of an atherosclerosis [11]. The causal relationship between periodontal disease and atherosclerosis can be identified through the presence of periopathogens within atheromatous plaques [12].

The aim of the present study was to determine the association between the presences of periopathogens, namely, P.g., A.a., T.f., T.d., and P.i., in subgingival and atheromatous plaques of coronary and carotid arteries in patients with chronic periodontitis, who were hospitalized and underwent surgery, by sampling DNA extract and amplification by polymerase chain reaction (PCR).

\section{Materials and Methods}

2.1. Patients. A total of 58 patients (male: 42 , female: 16) with chronic periodontal disease and atherosclerosis participated in this study. Patients were divided into two groups depending on the atherosclerotic blood vessel, either carotid or coronary arteries. Group I consisted of 30 patients (male: 22, female: 8 ) from 32 to 83 years of age (mean age: $54.5 \pm 14.8$ years) scheduled for carotid endarterectomy. Group II consisted of 28 patients (male: 20, female: 8 ) from 28 to 94 years of age (mean age: $63 \pm 12.1$ years) with coronary artery disease scheduled for coronary artery bypass graft surgery (CABG).

Regarding periodontal disease, patients were recruited only if they were with at least 4 periodontal pockets. Periodontal disease (PD) was diagnosed if the subject exhibited clinical attachment level $(\mathrm{CAL})>1 \mathrm{~mm}$ and periodontal pocket depth (PPD) $>3 \mathrm{~mm}$, at least at three sites in two different quadrants. According to CAL, patients with diagnosed PD were classified into two subgroups: patients with moderate chronic periodontitis $(\mathrm{CP})(\mathrm{CAL}=3-4 \mathrm{~mm})$ and severe $\mathrm{CP}(\mathrm{CAL} \geq 5 \mathrm{~mm})$. PD was defined as localized or generalized depending on the number of affected sites [13]. Peri- odontal examination was performed by one trained and calibrated periodontist (D.S.). Periodontal and surgical interventions were performed in the Clinic of Dental Medicine, Faculty of Medicine, Military Medical Academy, Belgrade; Clinic of Dental Medicine, Faculty of Medicine, Kosovska Mitrovica; and Clinic for Vascular and Endovascular Surgery, Clinical Center Serbia.

The exclusion criteria were smoking, pregnancy, presence of systemic diseases, use of medication (antibiotic or corticosteroids), and periodontal treatment within the past 3 months. The medical and dental history of each subject was obtained by interwiev. Patients fulfilling the inclusion criteria were fully informed about the study and signed an informed consent form that was approved by the Ethics Committee of the Medical Faculty Kosovska Mitrovica, Priština.

2.2. Subgingival and Atheromatous Plaque Sample. On the same day of the surgical intervention for carotid endarterectomy and CABG, a complete periodontal examination was performed. Clinical examinations included plaque index (PI) (according to Silness Löe), gingival index (GI) (according to Löe Silness), sulcus bleeding index (SBI) (according to Mühlemann Son), and periodontal pocket probing depth (PPD) [13-16]. The subgingival plaque samples were collected using the paper point technique (Periopaper, Amityville, Pro Flow, NY, USA) from the bottom of two out of four present periodontal pockets. Each sample site was isolated with cotton rolls, gently scaled supragingivaly and air dried. A sterile paper point was inserted into the apical extent of each selected pocket, kept for 60 seconds, and transferred immediately to a sterile Eppendorf tube and kept on $-70^{\circ} \mathrm{C}$ until the analysis.

The atheromatous plaque samples were obtained during the surgery, wherein the surgeon excised one or two small bits of atherosclerotic plaque from the edge of the blood vessel. In order to eliminate the blood contamination, the plaque samples were placed in a sterile Eppendorf tube with TrisEDTA as a transport medium, mixed gently, and kept on $-20^{\circ} \mathrm{C}$ until DNA preparation.

2.3. PCR Analysis. 16S rRNA PCR amplification was carried out to detect the presence of P.g., A.a., T.f., T.d., and P.i. in periodontal pockets and atherosclerotic vessels. The positive controls (American Type Culture Collection (ATCC)) consisted of DNA from pure cultures: P.g.-ATCC 33277, A.a.-ATCC 33384, T.f.-ATCC 43037, T.d.-ATCC 35405, and P.i.-ATCC 33563. PCR primers of microorganisms in the study are as listed in Table 1. Colonies obtained from cultures were suspended in sterile water and centrifuged and subjected to DNA extraction (positive control). Sterilized distilled water served as the negative control. $25 \mu \mathrm{l}$ of aqueous mixture containing $2.5 \mu \mathrm{l}$ of PCR buffer, $2.5 \mathrm{mM}$ $\mathrm{MgCl}_{2}, 0.2 \mathrm{mM}$ dNTPs, $0.2 \mu \mathrm{M}$ of species specific primers, $1 \mathrm{U}$ of DreamTaq DNA polymerase (all products from Thermo Fisher Scientific ${ }^{\mathrm{TM}}$; Waltham, MA, USA), and $5 \mu \mathrm{l}$ of bacterial DNA isolate was used for the reaction. The temperature profile of the bacteria was $95^{\circ} \mathrm{C}(3 \mathrm{~min}), 35$ cycles of $94^{\circ} \mathrm{C}(1 \mathrm{~min}), 60^{\circ} \mathrm{C}(1 \mathrm{~min})$, and $72^{\circ} \mathrm{C}(1 \mathrm{~min})$ and final 
TABLE 1: Bacteria primer sequences used in the polymerase chain reaction (PCR) detection.

\begin{tabular}{lr}
\hline Periopathogens & Product size \\
\hline Porphyromonas gingivalis $(P . g)$. & 400 bp \\
CAA TAC TCG TAT CGC CCG TTA TTC & \\
Aggregatibacter actinomycetemcomitans $($ A.a. $)$ & 600 bp \\
CAC TTA AAG GTC CGC CTA CGT GC & 840 bp \\
Tannerella forsythia $(T . f)$. & 316 bp \\
GTA GAG CTT ACA CTA TAT CGC AAA CTC CTA & 660 bp \\
Treponema denticola $($ T.d.) & \\
TAA TAC CGA ATG TGC TCA TTT ACA T TCA AAG AAG CAT TCC & \\
Prevotella intermedia $(P . i)$. &
\end{tabular}

extension at $72^{\circ} \mathrm{C}(7 \mathrm{~min})$. The $\mathrm{PCR}$ reaction was carried out using a PCR thermocycler (PeqSTAR, PeqLAB Biotechnologie $\mathrm{GmbH}$, Germany). After amplification, $10 \mu \mathrm{l}$ aliquot of the amplified PCR product was subjected to electrophoresis in $8 \%$ polyacrylamide gel ( $0.5 \mathrm{x}$ TAE buffer), stained with ethidium bromide, and finally visualized and photographed after exposure to UV light.

2.4. Statistical Analysis. The association between the periopathogens in the subgingival and atherosclerotic plaque samples was analyzed by calculating agreement statistics (absolute percentage agreement and Cohen's kappa statistic). The difference in average levels of various periodontal parameters between the patients with periopathogens present in both periodontal and arterial samples and those patients with negative results was tested using the Wilcoxon-MannWhitney test. $P$ values less than 0.05 were considered statistically significant. All analyses were performed within the statistical software environment R (v4.0.2; R Core Team 2018), by using package irr [17].

\section{Results}

A total of 58 patients (male: 42, female: 16) with periodontal disease and atherosclerosis participated in this study. Totally, 58 atherosclerotic plaque samples (30 from carotid and 28 from coronary arteries) and 58 subgingival plaque samples were examined and compared for the presence of five periopathogens (P.g., A.a., T.f., T.d., and P.i.).

The presence of DNA of five periopathogens in subgingival and atheromatous plaques of carotid and coronary arteries is presented in Tables 2 and 3.

In all cases, the bacterial species found in atherosclerotic plaques were also found in the subgingival plaques, although the presence of the periopathogens in subgingival plaque was not always associated with its presence in the atheromatous plaques of the same patients.

The frequencies of bacteria in subgingival versus atherosclerotic samples of carotid arteries were as follows: P.g. (53.3\%: 26.7\%), A.a. (36.7\%: 6.7\%), T.f. (80\%: 66.7\%), T.d. (33.3\%: 10.0\%), and P.i. (76.7\%: 20.0\%) (Table 2). We found a significant agreement of T.f. in subgingival plaque and carotid plaque samples (Table 2). The frequencies of bacteria in subgingival versus atherosclerotic samples of coronary arteries were as follows: P.g. (57.1\%: 39.3\%), A.a. (42.9\%: 25\%), T.f. (82.1\%: 46.4\%), T.d. (10.7\%: 7.1\%), and P.i. (67.9\%: 35.7\%) (Table 3). We found a significant agreement of P.g., A.a., and T.d. in subgingival plaque and coronary plaque samples (Table 3 ).

The present study further analyzed the mean value of the selected periodontal parameters, namely, plaque index, gingival index, sulcus bleeding index, and periodontal pocket depth in patients positive to the presence of periopathogens in carotid and coronary atheromatous plaques (Tables 4 and 5). As for relationship between the presences of periopathogens in the carotid atheromatous plaques, all clinical periodontal parameters analyzed were nonsignificant (Table 4). However, the results showed a statistically significant relationship between the presences of T.f. in the carotid atherosclerotic plaque with periodontal pocket depth values, while all other periodontal parameters analyzed were nonsignificant (Table 5).

\section{Discussion}

PD represents chronic inflammation in tooth-supportive tissues (periodontal ligament, connective tissue, and alveolar bone); that, if left untreated, leads to periodontal pocket formation and consequent bone loss [18]. It has been suggested that periodontitis-associated bacteraemias and systemic dissemination of inflammatory mediators produced in the periodontal tissues may cause a systemic inflammation. To date, many authors have demonstrated such a relationship [19, 20]. Atherosclerosis, as a progressive disease of the medium and large elastic and muscular arteries, can lead to ischemic lesions of the brain, heart, or extremities and can result in thrombosis and infarction of affected vessels [7-10]. Mechanisms that have been proposed to explain the link between PD and atherosclerotic cardiovascular disease include the inflammatory pathways common to both diseases (increased levels of white blood cells, C-reactive protein/CRP, fibrinogen, intercellular adhesion molecule-1, and proinflammatory cytokines). Additionally, both diseases share similar risk factors such as smoking, poor oral hygiene, diabetes mellitus, obesity, stress, and reduced physical activities [21].

Among 58 patients included in this study, 42 of them (72.4\%) were males, which make the prevalence of periodontal disease and atherosclerosis higher in man. Patients' mean age was 58.8 years. That is in correlation with common 
TABLE 2: Presence of periopathogens in subgingival and atheromatous plaque of carotid arteries.

\begin{tabular}{|c|c|c|c|c|c|c|}
\hline \multirow[t]{2}{*}{ Periopathogens } & \multirow[t]{2}{*}{ Subgingival plaque } & \multicolumn{2}{|c|}{$\begin{array}{c}\text { Atheromatous } \\
\text { plaque }\end{array}$} & \multirow[t]{2}{*}{$\%$ agreement } & \multirow[t]{2}{*}{ Kappa } & \multirow[t]{2}{*}{$P$ value } \\
\hline & & No & Yes & & & \\
\hline \multirow{2}{*}{ Porphyromonas gingivalis $(P . g)}$. & No & 14 & 0 & \multirow{2}{*}{73.3} & \multirow{2}{*}{0.48} & \multirow{2}{*}{0.002} \\
\hline & Yes & 8 & 8 & & & \\
\hline \multirow{2}{*}{$\begin{array}{l}\text { Aggregatibacter } \\
\text { actinomycetemcomitans (A.a.) }\end{array}$} & No & 19 & 0 & \multirow{2}{*}{70.0} & \multirow{2}{*}{0.22} & \multirow{2}{*}{0.054} \\
\hline & Yes & 9 & 2 & & & \\
\hline \multirow{2}{*}{ Tannerella forsythia (T.f.) } & No & 6 & 0 & \multirow{2}{*}{86.7} & \multirow{2}{*}{0.67} & \multirow{2}{*}{$<0.001$} \\
\hline & Yes & 4 & 20 & & & \\
\hline \multirow{2}{*}{ Treponema denticola (T.d.) } & No & 20 & 0 & \multirow{2}{*}{76.7} & \multirow{2}{*}{0.36} & \multirow{2}{*}{0.010} \\
\hline & Yes & 7 & 3 & & & \\
\hline \multirow{2}{*}{ Prevotella intermedia (P.i.) } & No & 7 & 0 & \multirow{2}{*}{43.3} & \multirow{2}{*}{0.14} & \multirow{2}{*}{0.131} \\
\hline & Yes & 17 & 6 & & & \\
\hline
\end{tabular}

TABLE 3: Presence of periopathogens in subgingival and atheromatous plaque of coronary arteries.

\begin{tabular}{|c|c|c|c|c|c|c|}
\hline \multirow[t]{2}{*}{ Periopathogens } & \multirow[t]{2}{*}{ Subgingival plaque } & \multicolumn{2}{|c|}{$\begin{array}{c}\text { Atheromatous } \\
\text { plaque }\end{array}$} & \multirow[t]{2}{*}{$\%$ agreement } & \multirow[t]{2}{*}{ Kappa } & \multirow[t]{2}{*}{$P$ value } \\
\hline & & No & Yes & & & \\
\hline \multirow{2}{*}{ Porphyromonas gingivalis (P.g.) } & No & 12 & 0 & \multirow{2}{*}{82.1} & \multirow{2}{*}{0.65} & \multirow{2}{*}{$<0.001$} \\
\hline & Yes & 5 & 11 & & & \\
\hline \multirow{2}{*}{$\begin{array}{l}\text { Aggregatibacter } \\
\text { actinomycetemcomitans (A.a.) }\end{array}$} & No & 16 & 0 & \multirow{2}{*}{82.1} & \multirow{2}{*}{0.62} & \multirow{2}{*}{$<0.001$} \\
\hline & Yes & 5 & 7 & & & \\
\hline \multirow{2}{*}{ Tannerella forsythia (T.f.) } & No & 5 & 0 & \multirow{2}{*}{64.3} & \multirow{2}{*}{0.32} & \multirow{2}{*}{0.022} \\
\hline & Yes & 10 & 13 & & & \\
\hline \multirow{2}{*}{ Treponema denticola (T.d.) } & No & 25 & 0 & \multirow{2}{*}{96.4} & \multirow{2}{*}{0.78} & \multirow{2}{*}{$<0.001$} \\
\hline & Yes & 1 & 2 & & & \\
\hline \multirow{2}{*}{ Prevotella intermedia (P.i.) } & No & 9 & 0 & \multirow{2}{*}{67.9} & \multirow{2}{*}{0.42} & \multirow{2}{*}{0.007} \\
\hline & Yes & 9 & 10 & & & \\
\hline
\end{tabular}

understanding of periodontal disease's progress. The age itself is not a predetermining risk factor for periodontal disease, but due to the lower number of elastic and collagen fibers as well as mitotic activity of fibroblasts, it is usually seen in adults over 40 years.

This study has proved the presence of peripathogen DNA in atheromatous plaques of coronary and carotid atheromatous and subgingival plaque samples of the same patients. The results are suggesting that periopathogens from subgingival plaque are most likely invading the systemic circulation and therefore were detected in atherosclerotic plaques of nearby heart blood vessels, suggesting its impact on the progression of atherosclerosis.

These results are in accordance with many published studies on this topic [20-31]. The data of this study were consistent with those reported by Haraszthy et al. [20] (26\% for P.g., $18 \%$ for A.a., 30\% positive for T.f., and 14\% for P.i.), Nakano et al. [21] by specific PCR (20\% for P.g., 35\% for A.a., and $20 \%$ T.d.), Figuero et al. [25] by nested PCR (78.6\% for P.g., $66.7 \%$ for A.a., and $61.9 \%$ T.f.), and Ohki et al. [26] (3.4\% for P.g., $19.7 \%$ for A.a., and $2.3 \%$ T.d.). In contrast to the present study and the results of other authors cited above, Cairo et al. [12], when examining 40 samples of atherosclerotic plaques (obtained after carotid endarterectomy) by PCR, did not detect the presence of any periodontal pathogenic bacteria. Aimetti et al. [32] did not isolate any periopathogens in samples taken from atherosclerotic carotid arteries of patients with periodontal disease. These discrepancies in the results from different studies may be associated with the study population, host immune response, and varying methods of sampling and laboratory analysis [27].

In our study, the presence of five periopathogens in carotid and coronary atherosclerotic vessels showed correlation in regard to degree of periodontal inflammation (Tables 4 and 5). Even though most of these correlations were not found to be significant, the prevalence of almost all periopathogens was higher in patients with moderate and severe periodontal disease when compared to patients with average PPD. The possible explanation for this correlation could be that moderate to severe periodontitis increases the level of systemic inflammation. Consequently, periodontal treatment could efficiently reduce clinical signs of the disease and 
TABLE 4: Clinical periodontal parameters for carotid arteries.

\begin{tabular}{|c|c|c|c|c|c|c|c|c|c|c|c|c|c|c|c|}
\hline Variable & $\begin{array}{l}\text { P.g. } \\
(+)\end{array}$ & $\begin{array}{c}\text { P.g. } \\
(-)\end{array}$ & $\begin{array}{c}P \\
\text { value }\end{array}$ & $\begin{array}{l}\text { A.a. } \\
(+)\end{array}$ & $\begin{array}{c}\text { A.a. } \\
(-)\end{array}$ & $\begin{array}{c}P \\
\text { value }\end{array}$ & $\begin{array}{l}\text { T.f. } \\
(+)\end{array}$ & $\begin{array}{l}\text { T.f. } \\
(-)\end{array}$ & $\begin{array}{c}P \\
\text { value }\end{array}$ & $\begin{array}{l}\text { T.d. } \\
(+)\end{array}$ & $\begin{array}{c}\text { T.d. } \\
(-)\end{array}$ & $\begin{array}{c}P \\
\text { value }\end{array}$ & $\begin{array}{l}P . i . \\
(+)\end{array}$ & $\begin{array}{l}\text { P.i. } \\
(-)\end{array}$ & $\begin{array}{c}P \\
\text { value }\end{array}$ \\
\hline \multicolumn{16}{|c|}{ Plaque index (PI) } \\
\hline Mean & 2.6 & 2.33 & \multirow{2}{*}{0.251} & 1.8 & 2.47 & \multirow{2}{*}{0.182} & 2.58 & 2.25 & \multirow{2}{*}{0.173} & 2.6 & 2.4 & \multirow{2}{*}{0.711} & 2.62 & 2.64 & \multirow{2}{*}{1} \\
\hline $\mathrm{SD}$ & 0.47 & 0.58 & & 0.42 & 0.53 & & 0.52 & 0.46 & & 0.52 & 0.54 & & 0.44 & 0.49 & \\
\hline \multicolumn{16}{|c|}{ Gingival index (GI) } \\
\hline Mean & 2.79 & 2.39 & \multirow{2}{*}{0.038} & 2 & 2.57 & \multirow{2}{*}{0.433} & 2.59 & 2.45 & \multirow{2}{*}{0.296} & 2.9 & 2.47 & \multirow{2}{*}{0.06} & 2.73 & 2.73 & \multirow{2}{*}{0.717} \\
\hline $\mathrm{SD}$ & 0.18 & 0.53 & & 1.13 & 0.39 & & 0.46 & 0.39 & & 0.1 & 0.47 & & 0.23 & 0.39 & \\
\hline \multicolumn{16}{|c|}{$\begin{array}{l}\text { Sulcus bleeding index } \\
\text { (SBI) }\end{array}$} \\
\hline Mean & 4.06 & 3.81 & \multirow{2}{*}{0.607} & 2.95 & 4.04 & \multirow{2}{*}{0.15} & 4.05 & 3.5 & \multirow{2}{*}{0.076} & 3.97 & 3.82 & \multirow{2}{*}{0.891} & 4.08 & 4.29 & \multirow{2}{*}{0.667} \\
\hline $\mathrm{SD}$ & 0.75 & 0.91 & & 1.34 & 0.69 & & 0.81 & 0.56 & & 1.05 & 0.77 & & 0.71 & 0.69 & \\
\hline \multicolumn{16}{|c|}{$\begin{array}{l}\text { Periodontal pocket depth } \\
(P P D)\end{array}$} \\
\hline Mean & 5.63 & 4.86 & \multirow{2}{*}{0.254} & 3.5 & 5.26 & \multirow{2}{*}{0.082} & 5.25 & 4.83 & \multirow{2}{*}{0.518} & 6 & 5 & \multirow{2}{*}{0.23} & 5.83 & 5.86 & \multirow{2}{*}{0.431} \\
\hline SD & 0.52 & 1.46 & & 0.71 & 1.19 & & 1.21 & 1.33 & & 1 & 1.26 & & 0.41 & 1.35 & \\
\hline
\end{tabular}

TABLE 5: Clinical periodontal parameters for coronary arteries.

\begin{tabular}{|c|c|c|c|c|c|c|c|c|c|c|c|c|c|c|c|}
\hline Variable & $\begin{array}{l}\text { P.g. } \\
(+)\end{array}$ & $\begin{array}{c}\text { P.g. } \\
(-)\end{array}$ & $\begin{array}{c}P \\
\text { value }\end{array}$ & $\begin{array}{c}\text { A.a. } \\
(+)\end{array}$ & $\begin{array}{c}\text { A.a. } \\
(-)\end{array}$ & $\begin{array}{c}P \\
\text { value }\end{array}$ & $\begin{array}{l}\text { T.f. } \\
(+)\end{array}$ & $\begin{array}{l}\text { T.f. } \\
(-)\end{array}$ & $\begin{array}{c}P \\
\text { value }\end{array}$ & $\begin{array}{l}\text { T.d. } \\
(+)\end{array}$ & $\begin{array}{c}\text { T.d. } \\
(-)\end{array}$ & $\begin{array}{c}P \\
\text { value }\end{array}$ & $\begin{array}{l}\text { P.i. } \\
(+)\end{array}$ & $\begin{array}{l}\text { P.i. } \\
(-)\end{array}$ & $\begin{array}{c}P \\
\text { value }\end{array}$ \\
\hline \multicolumn{16}{|c|}{ Plaque index (PI) } \\
\hline Mean & 2.53 & 2.11 & \multirow{2}{*}{0.057} & 2.73 & 2.15 & \multirow{2}{*}{0.058} & 2.58 & 2.22 & \multirow{2}{*}{0.194} & 2.5 & 2.26 & \multirow{2}{*}{0.53} & 2.47 & 2.44 & \multirow{2}{*}{1.000} \\
\hline $\mathrm{SD}$ & 0.65 & 0.59 & & 0.23 & 0.68 & & 0.44 & 0.6 & & 0.71 & 0.6 & & 0.43 & 0.53 & \\
\hline \multicolumn{16}{|c|}{ Gingival index (GI) } \\
\hline Mean & 2.58 & 2.36 & \multirow{2}{*}{0.172} & 2.32 & 2.28 & \multirow{2}{*}{0.085} & 2.37 & 2.38 & \multirow{2}{*}{0.103} & 2.85 & 2.45 & \multirow{2}{*}{0.394} & 1.65 & 2.49 & \multirow{2}{*}{0.675} \\
\hline SD & 0.59 & 0.85 & & 0.62 & 0.76 & & 0.27 & 0.79 & & 0.21 & 0.72 & & 0.31 & 0.79 & \\
\hline \multicolumn{16}{|c|}{$\begin{array}{l}\text { Sulcus bleeding index } \\
\text { (SBI) }\end{array}$} \\
\hline Mean & 3.93 & 3.29 & \multirow{2}{*}{0.117} & 3.65 & 3.38 & \multirow{2}{*}{0.252} & 4.09 & 3.07 & \multirow{2}{*}{0.086} & 4.45 & 3.48 & \multirow{2}{*}{0.128} & 3.85 & 3.77 & \multirow{2}{*}{0.82} \\
\hline SD & 0.88 & 0.97 & & 1.23 & 1.02 & & 0.6 & 1.2 & & 0.64 & 0.86 & & 0.67 & 0.8 & \\
\hline \multicolumn{16}{|c|}{$\begin{array}{l}\text { Periodontal pocket depth } \\
(P P D)\end{array}$} \\
\hline Mean & 5.73 & 4.38 & \multirow{2}{*}{0.015} & 5.25 & 4.59 & \multirow{2}{*}{0.021} & 6.08 & 4.33 & \multirow{2}{*}{0.004} & 6.5 & 4.77 & \multirow{2}{*}{0.21} & 6 & 4.8 & \multirow{2}{*}{0.057} \\
\hline $\mathrm{SD}$ & 1.35 & 1.39 & & 2.06 & 1.28 & & 1.12 & 0.82 & & 2.12 & 1.24 & & 1.25 & 1.23 & \\
\hline
\end{tabular}

decrease the level of systemic inflammatory mediators. Therefore, further studies with a larger number of patients related to prevention or treatment of periodontal disease that would result in reduced mortality and morbidity associated with atherosclerosis are necessary. Further in vitro, in vivo, and clinical studies with precise bacterial quantification with longer follow-up are essential in order to confirm the causal relationship between PD and atherosclerosis.

\section{Conclusion}

The present study suggests the relationship between periodontal pathogenic bacteria and atherogenesis. Even though the presence of periopathogens may not be the only factor that causes inflammatory disease associated with atherosclerosis, it should be considered a potential risk factor.

\section{Data Availability}

Data are available from the corresponding author upon request.

\section{Conflicts of Interest}

No conflict of interest exists.

\section{Acknowledgments}

The authors wish to thank to Prof. Sinisa Lakic, University of Banja Luka, Bosnia and Herzegovina, for his kind support in manuscript preparation. 


\section{References}

[1] S. Schützhold, T. Kocher, R. Biffar et al., "Changes in prevalence of periodontitis in two German population-based studies," Journal of Clinical Periodontology, vol. 42, no. 2, pp. 121-130, 2015.

[2] A. Pucar, J. Milasin, V. Lekovic et al., "Correlation between atherosclerosis and periodontal putative pathogenic bacterial infections in coronary and internal mammary arteries," Journal of Periodontology, vol. 78, no. 4, pp. 677-682, 2007.

[3] E. Koshi, S. Rajesh, P. Koshi, and P. R. Arunima, "Risk assessment for periodontal disease," Journal of Indian Society of Periodontology, vol. 16, no. 3, pp. 324-328, 2012.

[4] N. D. Perunovic, M. M. Rakic, L. I. Nikolic et al., "The association between periodontal inflammation and labor triggers (elevated cytokine levels) in preterm birth: a cross-sectional study," Journal of Periodontology, vol. 87, no. 3, pp. 248-256, 2016.

[5] S. M. Petrovic, N. Nikolic, B. Toljic et al., "The association of tumor necrosis factor alpha, lymphotoxin alpha, tumor necrosis factor receptor 1 and tumor necrosis factor receptor 2 gene polymorphisms and serum levels with periodontitis and type 2 diabetes in Serbian population," Archives of Oral Biology, vol. 120, p. 104929, 2020.

[6] K. Matsushita, M. Yamada-Furukawa, M. Kurosawa, and Y. Shikama, "Periodontal disease and periodontal diseaserelated bacteria involved in the pathogenesis of Alzheimer's sisease," Journal of Inflammation Research, vol. 13, pp. 275283, 2020.

[7] J. D. Beck, R. Garsia, G. Heiss, P. Vokonas, and S. Ofenbacher, "Periodontal disease and cardiovascular disease," Journal of Periodontology, vol. 67, no. 10, pp. 11231137, 1996.

[8] F. De Stefano, R. F. Anda, H. S. Kahn, D. F. Williamson, and C. M. Russell, "Dental disease and risk of coronary heart disease and mortality," BMJ., vol. 306, pp. 688-691, 1993.

[9] J. Chhibber-Goel, V. Singhal, D. Bhowmik et al., "Linkages between oral commensal bacteria and atherosclerotic plaques in coronary artery disease patients," NPJ Biofilms Microbiomes., vol. 2, no. 1, 2016.

[10] P. Libby, "The vascular biology of aterosclerosos," in Braunwald's Heart Disease, P. Libby, R. O. Bonow, D. L. Mann, D. Zipes, and E. Braunwald, Eds., pp. 985-1002, Sounders Elsevier, Philadelphia, Eight edition, 2008.

[11] V. Friedrich, S. Pubingers, T. Chen, P. Messner, F. E. Dewhirst, and C. Schäffer, "Draft Genome Sequence of Tannerella forsythia Type Strain ATCC 43037," Genome Announcements, vol. 3, no. 3, 2015.

[12] F. Cairo, S. Castellani, A. M. Gori et al., "Severe periodontitis in young adults is associated with sub-clinical atherosclerosis," Journal of Clinical Periodontology, vol. 35, no. 6, pp. 465472, 2008.

[13] G. C. Armitage, "Development of a classification system for periodontal diseases and conditions," Annals of Periodontology, vol. 4, pp. 1-6, 1999.

[14] J. Silness and H. Loe, "Periodontal diseases in pregnancy. II. Correlation between oral hygiene and periodontal condition," Acta Odontologica Scandinavica, vol. 22, no. 1, pp. 121-135, 1964.

[15] H. Loe and J. Silness, "Periodontal disease in pregnancy. I. Prevalence and severity," Acta Odontologica Scandinavica, vol. 21, no. 6, pp. 533-551, 1963.
[16] H. R. Mühlemann and S. Son, "Gingival sulcus bleeding-a leading symptom in initial gingivitis," Helvetica Odontologica Acta, vol. 15, no. 2, pp. 107-113, 1971.

[17] M. Gamer, J. Lemon, M. M. Gamer, A. Robinson, and W. Kendall's, "Package 'irr'," Various coefficients of interrater reliability and agreement., vol. 22, 2012.

[18] P. N. Papapanou, "Systemic effects of periodontitis: lessons learned from research on atherosclerotic vascular disease and adverse pregnancy outcomes," International Dental Journal, vol. 65, no. 6, pp. 283-291, 2015.

[19] K. Mahalakshmi, P. Krishnan, and S. B. Arumugam, “Association of periodontopathic anaerobic bacterial co-occurrence to atherosclerosis-a cross-sectional study," Anaerobe, vol. 44, pp. 66-72, 2017.

[20] V. I. Haraszthy, J. J. Zambon, M. Trevisan, M. Zeid, and R. J. Genco, "Identification of periodontal pathogens in atheromatous plaques," Journal of Periodontology, vol. 71, no. 10, pp. 1554-1560, 2000.

[21] K. Nakano, H. Inaba, R. Nomura et al., "Detection of cariogenic Streptococcus mutans in extirpated heart valve and atheromatous plaque specimens," Journal of Clinical Microbiology, vol. 44, no. 9, pp. 3313-3317, 2006.

[22] C. Padilla, O. Lobos, E. Hubert et al., "Periodontal pathogens in atheromatous plaques isolated from patients with chronic periodontitis," Journal of Periodontal Research, vol. 41, no. 4, pp. 350-353, 2006.

[23] I. Gotsman, C. Lotan, W. A. Soskolne et al., "Periodontal destruction is associated with coronary artery disease and periodontal infection with acute coronary syndrome," Journal of Periodontology, vol. 78, no. 5, pp. 849-858, 2007.

[24] Y. M. Zhang, L. J. Zhong, P. Liang, H. Liu, L. T. Mu, and S. K. $\mathrm{Ai}$, "Relationship between microorganisms in coronary atheromatous plaques and periodontal pathogenic bacteria," Chinese Medical Journal, vol. 121, no. 16, pp. 1595-1597, 2008.

[25] E. Figuero, M. Sánchez-Beltrán, S. Cuesta-Frechoso et al., "Detection of periodontal bacteria in atheromatous plaque by nested polymerase chain," Journal of Periodontology, vol. 82, no. 10, pp. 1469-1477, 2011.

[26] T. Ohki, Y. Itabashi, T. Kohno et al., "Detection of periodontal bacteria in thrombi of patients with acute myocardial infarction by polymerase chain reaction," American Heart Journal, vol. 163, no. 2, pp. 164-167, 2012.

[27] M. Szulc, W. Kustrzycki, D. Janczak, D. Michalowska, D. Baczynska, and M. Radwan-Oczko, "Presence of periodontopathic bacteria DNA in atheromatous plaques from coronary and carotid arteries," BioMed Research International, vol. 2015, Article ID 825397, 6 pages, 2015.

[28] D. A. Chistiakov, A. N. Orekhov, and Y. V. Bobryshev, "Links between atherosclerotic and periodontal disease," Experimental and Molecular Pathology, vol. 100, no. 1, pp. 220-235, 2016.

[29] K. Okuda, K. Ishihara, T. Nakagawa, A. Hirayama, Y. Inayama, and K. Okuda, "Detection of Treponema denticola in atherosclerotic lesions," Journal of Clinical Microbiology, vol. 39, no. 3, pp. 1114-1117, 2001.

[30] K. Ishihara, A. Nabuchi, R. Ito, K. Miyachi, H. K. Kuramitsu, and K. Okuda, "Correlation between Detection Rates of Periodontopathic Bacterial DNA in Carotid Coronary Stenotic Artery Plaque and in Dental Plaque Samples," Journal of Clinical Microbiology, vol. 42, no. 3, pp. 1313-1315, 2004. 
[31] I. Kannosh, D. Staletovic, B. Toljic et al., "The presence of periopathogenic bacteria in subgingival and atherosclerotic plaques - an age related comparative analysis," The Journal of Infection in Developing Countries, vol. 12, no. 12, pp. 10881095, 2018.

[32] M. Aimetti, F. Romano, and F. Nessi, "Microbiologic analysis of periodontal pockets and carotid atheromatous plaques in advanced chronic periodontitis patients," Journal of Periodontology, vol. 78, no. 9, pp. 1718-1723, 2007. 